\title{
The Relationship among Middle-aged Crisis, Wisdom, Savoring Beliefs, Interpersonal Harmony and Life Satisfaction
}

\author{
SooHong Chae1) HyounYong Kwon²)
}

\begin{abstract}
The purpose of this study is to investigate the relationship between Middle-aged crisis, wisdom, savoring belief, interpersonal harmony, and life satisfaction. To this end, a survey was conducted using a random sampling method to 600 middle-aged adults aged 40-65 who live in Seoul, Gyeonggi, Gangwon, Chungcheong, Jeolla, Gyeongsang, and Jeju. The data collected in this study were analyzed using SPSS 25.0 and SmartPLS 3.0 programs. The research results are as follows. First, as a result of examining the differences to the demographic and statistical characteristics of the middle age, women experienced higher Middle-aged crisis than men, and there were difficulties in interpersonal harmony. The older they were, the higher their wisdom, savoring beliefs, interpersonal harmony, and life satisfaction. Second, Middle-aged crisis had negative correlations with wisdom, savoring belief, interpersonal harmony and life satisfaction, and Wisdom, savoring belief, and interpersonal harmony had a positive correlation with life satisfaction. Third, as a result of examining how Middle-aged crisis, wisdom, savoring belief, and interpersonal harmony affect life satisfaction, the sub-factor of Middle-aged crisis that had the highest negative impact on life satisfaction was life dissatisfaction. The sub-factors of Middle-aged crisis that had a positive effect on life satisfaction were in the order of present enjoyment, interpersonal emotional factors, and positive life attitude. Fourth, Middle-aged crisis has a significant effect on life satisfaction through mediation of wisdom, savoring belief, and interpersonal harmony. Through the results of this study, it is expected to understand the characteristics related to Middle-aged crisis and life satisfaction. Moreover, it is intended to be used in providing basic data for developing a program that can overcome the Middle-aged crisis and improve life satisfaction.
\end{abstract}

Keywords: Middle-aged Crisis, Wisdom, Enjoyment, Interpersonal Relationship, Life Satisfaction

\section{Introduction}

In most countries, life expectancy is increasing due to the improvement of living environment, the improvement of education level and the development of medical service, and the average life expectancy of Korea is among the highest among OECD countries. In 2004, the number of

Received(June 3, 2020), Review Result(1st: July 25, 2020, 2nd: September 10, 2020), Accepted(October 28, 2020)

1) (Doctor) 18330 Dept. General Graduate School, Hyupsung Univ., 72, Choerubaek-ro, Bongdam-eup, Hwaseong-si, Gyeonggi-do, Korea

email: chaesh_2000@hanmail.net

2) (Professor, Corresponding Author) 18330 Dept. Liberal Arts \& Education, Hyupsung Univ., 72, Choerubaek-ro, Bongdam-eup, Hwaseong-si, Gyeonggi-do, Korea

email: khyong@hanmail.net 
the elderly aged 65 or over was 4.13 million, accounting for $10.9 \%$ of the total productive population. However, it continued to rise, and in 2017, about 3 million people increased to 707 million (16.1\%)[1]. The increase in life expectancy suggests that, in addition to the increase in the middle-aged population and the number of the elderly, the life span of the middle and old age is getting longer together. Everyone has the expectation and psychology to live a happy and healthy life. However, they are experiencing many emotional and economic crises due to changes in social structure and economic distress, such as layoffs, early retirement, nuclear familyization and the spread of individualist values.

In Korea, due to the rapid aging, the quality of life of elderly people, that is, life satisfaction, has become very important not only for individuals but also for society. Life Satisfaction means the degree of satisfaction of the elderly from the past to the present, or the degree of satisfaction with happiness, or the attitude and subjective and comprehensive satisfaction of their past or present life, which the individual perceives. How to improve the quality of life and how to improve life satisfaction is a prerequisite to be solved[2]. In today's life satisfaction, as various values dominate our lives, the differences in values among family members are intensifying, the bonds between members are weakened, the cultural consciousness is delayed among the three generations, and the heterogeneity between parents and children is growing[3].

Middle-age is the middle of when you divide your life into the former and latter half, and it is the middle generation between young and old generation[4]. Until the twentieth century, the intermediary process was not long from the early adulthood to the beginning of old age, but as the life expectancy increases over the course of a century and the health and vitality increase, the middle age is also lengthening.

Middle-aged age is a more mature period that goes beyond individualism and takes care of other people or the next generation with care and responsibility. It is also a time to experience crises[5]. Problems and alienation in relations with people lead to a break in dialogue, and at home, marital discord, divorce, and generational conflict between parents and children[6].

Wisdom's function, which has recently gained attention in the field of positive psychology, ranges from making important decisions in the lives of individuals to guiding and advising others and to problem-solving skills. Wisdom serves as a guide to the increasingly complex social structures and directions in our lives with so many values. Wisdom influences the overcoming of hard experiences such as physical and psychological loss in middle age and old age, and affects life satisfaction, well-being, and relationships with others such as family[7]. In positive psychology, an approach to scientific research on the positive aspects of human beings 
has been taken from the study of the negative aspects of human beings, and attention is paid to human happiness, strengths, and cultivation of virtues[8]. Savoring, one of the ways to promote happiness, satisfies and satisfies the positive experiences we encounter in our lives[9]. Savoring is all the process that leads people to positively enjoy and enrich their positive experiences. Through social relations, human beings are able to express their capabilities and make their lives richer and more vibrant. In particular, interpersonal relationships, which are the core of social relations, are important variables for adults in middle age to feel conviction and reward for their existence[10]. The purpose of this study is to examine the relationship among Middle-aged crisis, wisdom, savoring beliefs, interpersonal harmony, and life satisfaction. This study is intended to deepen the understanding on the concept of Middle-aged crisis and could provide basic data for realistic support and better life satisfaction.

The following research questions were established to clarify on the relationship among Middle-aged crisis, wisdom, savoring beliefs, interpersonal harmony, and life satisfaction.

1) Are there differences in Middle-aged crisis, wisdom, savoring beliefs, interpersonal harmony, and life satisfaction according to demographic characteristics of middle age?

2) How does Middle-aged crisis, wisdom, savoring beliefs and interpersonal harmony relate to life satisfaction?

3) How do Middle-aged crisis, wisdom, savoring beliefs and interpersonal harmony affect life satisfaction?

4) Does wisdom, enjoyment, and interpersonal harmony play a mediating role in the relationship between Middle-aged crisis and life satisfaction?

\section{Research Method}

\subsection{Subjects}

The demographic characteristics of subjects are presented in [Table 1]. The gender was 277 male $(48.9 \%)$ and 289 female (51.1\%). The ages were 220 in 40s (38.9\%), 229 in 50s (40.5\%), and 117 in over $60 \mathrm{~s}(20.7 \%)$. The marital status was 517 married $(91.3 \%), 8$ widows $(1.4 \%), 4$ separated $(0.7 \%)$, and 37 divorced (6.5\%). Academic achievement was found to be $100(17.7 \%)$ graduated from high school, 94 (16.6\%) graduated from college, 305 (53.9\%) graduated from four years, and $67(11.8 \%)$ graduated from graduate school. 
[Table 1] The Demographic Characteristics of Subjects

$(\mathrm{N}=556)$

\begin{tabular}{llcc}
\hline division & & $\mathrm{N}$ & $\%$ \\
\hline \hline \multirow{2}{*}{ gender } & male & 277 & 48.9 \\
& female & 289 & 51.1 \\
\hline \multirow{3}{*}{ age } & $40 \mathrm{~s}$ & 220 & 38.9 \\
& $50 \mathrm{~s}$ & 229 & 40.5 \\
& over 60s & 117 & 20.7 \\
\hline \multirow{4}{*}{ marital status } & married & 517 & 91.3 \\
& widows & 8 & 1.4 \\
& separated & 4 & 0.7 \\
& divorced & 37 & 6.5 \\
\hline \multirow{4}{*}{ Academic achievement } & graduated from college & 100 & 17.7 \\
& graduated from four years & 94 & 16.6 \\
& graduated from graduate school & 305 & 53.9 \\
& & 67 & 11.8 \\
\hline
\end{tabular}

\subsection{Measurement Scale}

\section{Middle-aged Crisis Scale}

The Middle-aged crisis scale was developed by Kim Ae-soon and Yoon Jin[11], and reconstructed by Hong Dal-Ah and Lee Nam-joo[12]. The five sub-factors are emotional crisis, loss of vitality, life dissatisfaction, marital dissatisfaction, and child relationship dissatisfaction. It consists of 34 questions. The overall internal consistency was Cronbach 's $\alpha=.93$.

\section{Life Satisfaction Scale}

The Life Satisfaction Scale was developed by Yang Ok-kyung[13] and used the scale used in Oh Seung-ha's study[3]. The four sub-factors are physical and mental health, social and leisure activities, happiness, autonomy and self-esteem, and are self-reported tests on the Likert 5-point scale. There are 15 questions in total. Internal consistency was Cronbach 's $\alpha=.92$.

\section{Wisdom Scale}

To measure wisdom, we used the wisdom scale developed by Min-hee Kim[14]. Four sub-factors are cognitive competence, moderation and balance, positive life attitude, and empathic interpersonal relationship. There are a total of 43 questions. Overall internal consistency was Cronbach 's $\alpha=.96$.

\section{Savoring Belief Scale}

In order to measure savoring belief, Bryant and Veroff[15] developed a scale that was revised and validated by Cho Hyun-seok[16]. The three sub-factors are Future Expectation, Present Enjoyment, and Past Recall, and are self-reported tests on the Likert 7-point scale. There are a total of 24 questions. The overall internal fit was Cronbach 's $\alpha=.93$. 
The interpersonal harmony scale was developed by Kim Sung-hoe and Park Kyung-hee[17]. Three sub-factors are interpersonal cognitive factors, interpersonal emotional factors, and interpersonal behavioral factors. They are self-reported tests made of the Likert 5-point scale. There are a total of 28 questions. Internal consistency was Cronbach 's $\alpha=.85$.

\subsection{Analysis of Materials}

The data collected in this study were analyzed using SPSS 25.0 and SmartPLS 3.0 programs. First, frequency analysis was conducted to confirm the demographic characteristics of the study subjects. Second, multiple regression analysis was conducted to verify the effect of dependent variables on independent variables and sub-factors of parameters. Third, the PLS structural equation model analysis evaluated the validity of the measurement model and the fit of the structural model, and then verified the path coefficients corresponding to the research questions.

\section{Results}

\subsection{The Demographic Characteristic Differences}

Independent sample $\mathrm{t}$-test was performed to verify the difference of major variables according to gender and the results are presented in [Table 2]. As a result of the analysis, there was a significant difference in Middle-aged crisis $(\mathrm{t}=-2.00, \mathrm{p}<.05)$ and interpersonal harmony $(\mathrm{t}=$ $-2.04, \mathrm{p}<.05)$ by gender.

[Table 2] Differences in Major Variables According to Gender

\begin{tabular}{ccccc}
\hline Variable & Gender & $\mathrm{N}$ & $\mathrm{M} \pm \mathrm{SD}$ & $\mathrm{t}(\mathrm{p})$ \\
\hline \hline \multirow{2}{*}{ Middle-aged crisis } & Male & 277 & $2.98 \pm .51$ & \multirow{2}{*}{$-2.00^{*}$} \\
& Female & 289 & $3.07 \pm .53$ & \multirow{2}{*}{.73} \\
\hline \multirow{2}{*}{ wisdom } & Male & 277 & $3.38 \pm .43$ & \multirow{2}{*}{-1.21} \\
& Female & 289 & $3.35 \pm .45$ & \multirow{2}{*}{$-2.04^{*}$} \\
\hline \multirow{2}{*}{ savoring beliefs } & Male & 277 & $4.66 \pm .69$ & \multirow{2}{*}{-.35} \\
& Female & 289 & $4.73 \pm .43$ & \\
\hline \multirow{2}{*}{ interpersonal harmony } & Male & 277 & $3.56 \pm .37$ & \\
\hline \multirow{2}{*}{ life satisfaction } & Female & 289 & $3.63 \pm .39$ & $3.06 \pm .59$ \\
& Male & 277 & $3.07 \pm .57$ & \\
${ }^{*} p<.05$ & Female & 289 & &
\end{tabular}


One-way ANOVA was performed to verify the differences in major variables according to age, and the results are presented in [Table 3]. As a result of analysis, wisdom according to age $(F=12.64, p<.001)$, savoring belief $(F=4.94, p<.01)$, interpersonal harmony $(F=4.95, p$ $<.01)$, and life satisfaction $(\mathrm{F}=10.75, \mathrm{p}<.001)$ was found to be significant.

[Table 3] Differences in Major Variables According to Age

\begin{tabular}{|c|c|c|c|c|c|}
\hline Variable & Age & $\mathrm{N}$ & $\mathrm{M} \pm \mathrm{SD}$ & $\mathrm{F}(\mathrm{p})$ & Scheffe \\
\hline \multirow{3}{*}{ Middle-aged crisis } & $40 \mathrm{~s}(\mathrm{a})$ & 220 & $3.05 \pm .54$ & \multirow{3}{*}{$\begin{array}{c}.77 \\
(.463)\end{array}$} & \multirow{3}{*}{ - } \\
\hline & $50 \mathrm{~s}(\mathrm{~b})$ & 229 & $3.03 \pm .53$ & & \\
\hline & Over $60(c)$ & 117 & $2.98 \pm .46$ & & \\
\hline \multirow{3}{*}{ wisdom } & $40 \mathrm{~s}(\mathrm{a})$ & 220 & $3.27 \pm .43$ & \multirow{3}{*}{$\begin{array}{c}12.64^{* * *} \\
(.000)\end{array}$} & \multirow{3}{*}{$c>b>a$} \\
\hline & $50 s(b)$ & 229 & $3.38 \pm .42$ & & \\
\hline & Over $60(c)$ & 117 & $3.51 \pm .43$ & & \\
\hline \multirow{3}{*}{ savoring beliefs } & $40 \mathrm{~s}(\mathrm{a})$ & 220 & $4.63 \pm .73$ & \multirow{3}{*}{$\begin{array}{l}4.94^{* *} \\
(.007)\end{array}$} & \multirow{3}{*}{$c>b, a$} \\
\hline & $50 \mathrm{~s}(\mathrm{~b})$ & 229 & $4.66 \pm .69$ & & \\
\hline & Over $60(\mathrm{c})$ & 117 & $4.88 \pm .68$ & & \\
\hline \multirow{3}{*}{$\begin{array}{c}\text { interpersonal } \\
\text { harmony }\end{array}$} & $40 \mathrm{~s}(\mathrm{a})$ & 220 & $3.53 \pm .40$ & \multirow{3}{*}{$\begin{array}{l}4.95^{* *} \\
(.007)\end{array}$} & \multirow{3}{*}{$c>a$} \\
\hline & $50 \mathrm{~s}(\mathrm{~b})$ & 229 & $3.62 \pm .36$ & & \\
\hline & Over $60(c)$ & 117 & $3.66 \pm .37$ & & \\
\hline \multirow{3}{*}{ life satisfaction } & $40 \mathrm{~s}(\mathrm{a})$ & 220 & $2.94 \pm .56$ & \multirow{3}{*}{$\begin{array}{c}10.75^{* * *} \\
(.000)\end{array}$} & \multirow{3}{*}{$c, b>a$} \\
\hline & $50 s(b)$ & 229 & $3.11 \pm .59$ & & \\
\hline & Over $60(\mathrm{c})$ & 117 & $3.27 \pm .56$ & & \\
\hline
\end{tabular}

\subsection{Multiple Regression Analysis}

Multiple regression analysis was conducted to verify the effects of Middle-aged crisis on the life satisfaction, and the results are presented in [Table 4]. As a result, emotional crisis $(\beta=-$. $15, \mathrm{p}<.001)$, loss of vitality $(\beta=-.29, \mathrm{p}<.001)$, life dissatisfaction $(\beta=-.50, \mathrm{p}<.001)$, Marital dissatisfaction $(\beta=-.10, p<.01)$, and child relationship dissatisfaction $(\beta=-.14, p<.001)$ all showed a significant explanation of life satisfaction. The magnitude of influence was found in the order of life dissatisfaction, loss of vitality, emotional crisis, child relationship dissatisfaction, marital dissatisfaction, and explanation power was $60.8 \%$.

[Table 4] The Effects of Middle-aged Crisis on the Life Satisfaction

\begin{tabular}{ccccccccc}
\hline Variable & $\mathrm{B}$ & $\mathrm{SE}$ & $\beta$ & $\mathrm{t}$ & $\mathrm{VIF}$ & $\mathrm{D}-\mathrm{W}$ & $\mathrm{R} 2$ & $\mathrm{~F}$ \\
\hline \hline emotional crisis & -.16 & .04 & -.15 & $-3.56^{* * *}$ & 2.43 & & & \\
loss of vitality & -.22 & .03 & -.29 & $-6.68^{* * *}$ & 2.73 & & & \\
& & & & & & & & \\
\hline
\end{tabular}




$\begin{array}{cccccc}\text { life dissatisfaction } & -.48 & .03 & -.50 & -16.82^{* * *} & 1.27 \\ \text { marital dissatisfaction } & -.07 & .03 & -.10 & -2.69^{* *} & 1.77 \\ \begin{array}{c}\text { child relationship } \\ \text { dissatisfaction }\end{array} & -.11 & .02 & -.14 & -4.36^{* * *} & 1.54\end{array}$

${ }^{* *} \mathrm{p}<.01,{ }^{* * *} \mathrm{p}<.001$

The effect of wisdom on life satisfaction is presented in [Table 5]. As a result, cognitive competence $(\beta=.15, \mathrm{p}<.05)$, moderation and balance $(\beta=.25, \mathrm{p}<.001)$, positive life attitude $(\beta=.54, p<.001)$, empathic interpersonal relationship $(\beta=.11, p<.05)$ were found to explain life satisfaction significantly. Specifically, the higher the sub-factor of wisdom, the higher the satisfaction of life, and the magnitude of influence was found in the order of positive life attitude, moderation and balance, cognitive competence, and empathic interpersonal relationship. The explanatory power was $30.6 \%$.

[Table 5] The Effects of Wisdom on the Life Satisfaction

\begin{tabular}{ccccccccc}
\hline Variable & $\mathrm{B}$ & $\mathrm{SE}$ & $\beta$ & $\mathrm{t}$ & $\mathrm{VIF}$ & $\mathrm{D}-\mathrm{W}$ & $\mathrm{R} 2$ & $\mathrm{~F}$ \\
\hline \hline cognitive competence & .18 & .07 & .15 & $2.52^{*}$ & 3.02 & & & \\
moderation and balance & .30 & .08 & .25 & $3.82^{* * *}$ & 3.34 & & & \\
positive life attitude & .62 & .07 & .54 & $8.35^{* * *}$ & 3.37 & 2.00 & .306 & $61.89^{* * *}$ \\
empathic interpersonal & .13 & .07 & .11 & $2.03^{*}$ & 2.28 & & & \\
$\quad$ relationship & & & & & & & & \\
\hline${ }^{*} \mathrm{p}<.05,{ }^{* * *} \mathrm{p}<.001$ & & & & & &
\end{tabular}

The influence of sub-factors of savoring belief on life satisfaction is presented in [Table 6]. As a result, only the present enjoyment $(\beta=.60, p<.001)$ among the sub-factors of savoring belief significantly explained life satisfaction. Specifically, the higher the present enjoyment, the higher the life satisfaction was, and the explanatory power was $20.7 \%$.

[Table 6] The Effects of Savoring Belief on the Life Satisfaction

\begin{tabular}{ccccccccc}
\hline Variable & $\mathrm{B}$ & $\mathrm{SE}$ & $\beta$ & $\mathrm{t}$ & $\mathrm{VIF}$ & $\mathrm{D}-\mathrm{W}$ & $\mathrm{R} 2$ & $\mathrm{~F}$ \\
\hline \hline past recall & -.06 & .05 & -.08 & -1.14 & 3.54 & & & \\
present enjoyment & .44 & .05 & .60 & $8.48^{* * *}$ & 3.50 & 2.00 & .207 & $49.01^{* * *}$ \\
future expectation & -.09 & .06 & -.11 & -1.36 & 4.32 & & & \\
\hline$* * * \mathrm{p}<.001$ & & & & & & &
\end{tabular}

The effects of subfactors of interpersonal harmony on life satisfaction are presented in [Table 7]. As a result, only the interpersonal emotional factors $(\beta=.55, \mathrm{p}<.001)$ among the sub-factors of interpersonal harmony were found to explain the life satisfaction significantly. Specifically, the higher the interpersonal emotional factors, the higher the life satisfaction. The 
explanatory power was $28.0 \%$.

[Table 7] The Effects of Interpersonal Harmony on the Life Satisfaction

\begin{tabular}{lcccccccc}
\hline Variable & $\mathrm{B}$ & $\mathrm{SE}$ & $\beta$ & $\mathrm{t}$ & $\mathrm{VIF}$ & $\mathrm{D}-\mathrm{W}$ & $\mathrm{R} 2$ & $\mathrm{~F}$ \\
\hline \hline interpersonal cognitive factors & -.03 & .06 & -.02 & -.48 & 1.47 & & & \\
interpersonal emotional factors & .71 & .06 & .55 & $10.86^{* * *}$ & 1.98 & 2.00 & .280 & $72.82^{* * *}$ \\
interpersonal behavioral factors & -.02 & .07 & -.01 & -.24 & 2.07 & & & \\
\hline${ }^{* * *} \mathrm{p}<.001$ & & & & & & &
\end{tabular}

\subsection{Mediation Effect Verification}

The results of the evaluation of the model were found to be good. Bootstrapping was performed and the estimated direct path coefficients are presented in [Table 8]. As a result of the analysis, it was found that Middle-aged crisis negatively explained wisdom $(\beta=-.33, p$ $<.001)$, savoring belief $(\beta=-.47, \mathrm{p}<.001)$, and interpersonal harmony $(\beta=-.37, \mathrm{p}<.001)$. In other words, the higher Middle-aged crisis, the lower the harmony of wisdom, savoring beliefs and interpersonal harmony. Wisdom $(\beta=.31, \mathrm{p}<.001)$, savoring beliefs $(\beta=.17, \mathrm{p}<.001)$, and interpersonal harmony $(\beta=.19, \mathrm{p}<.001)$ are all statically significant.

[Table 8] Estimation of Direct Path Coefficients of the Research Model

\begin{tabular}{ccccc}
\hline Path & $\beta$ & SD & $\mathrm{t}$ & $\mathrm{p}$ \\
\hline \hline Middle-aged crisis $\rightarrow$ wisdom & -.33 & .04 & $7.60^{* * *}$ & .000 \\
Middle-aged crisis $\rightarrow$ savoring beliefs & -.47 & .03 & $14.47^{* * *}$ & .000 \\
Middle-aged crisis $\rightarrow$ interpersonal harmony & -.37 & .04 & $9.74^{* * *}$ & .000 \\
wisdom $\rightarrow$ life satisfaction & .31 & .05 & $5.76^{* * *}$ & .000 \\
savoring beliefs $\rightarrow$ life satisfaction & .17 & .05 & $3.78^{* * *}$ & .000 \\
interpersonal harmony $\rightarrow$ life satisfaction & .19 & .06 & $3.45^{* *}$ & .001 \\
\hline
\end{tabular}

${ }^{* *} \mathrm{p}<.01,{ }^{* * *} \mathrm{p}<.001$

Next, the results of estimating the indirect path are shown in [Table 9]. The Middle-aged crisis had a significant effect on life satisfaction $(\beta=-.10, p<.001)$ through wisdom, and Middle-aged crisis had a positive impact on life satisfaction $(\beta=-.08, p<.01)$ through savoring beliefs. It has been shown to have a significant effect. In addition, Middle-aged crisis was found to have a significant effect on life satisfaction $(\beta=-.07, p<.01)$ through interpersonal harmony. Thus, wisdom, savoring beliefs, and interpersonal harmony all mediate the relationship between Middle-aged crisis and life satisfaction. 
[Table 9] Estimation of Indirect Path Coefficients of the Research Model

http://dx.doi.org/10.47116/apjcri.2020.11.10

\begin{tabular}{ccccc} 
Path & $\beta$ & $\mathrm{SD}$ & $\mathrm{t}$ & $\mathrm{p}$ \\
\hline \hline Middle-aged crisis $\rightarrow$ wisdom $\rightarrow$ life satisfaction & -.10 & .03 & $3.94^{* * *}$ & .000 \\
Middle-aged crisis $\rightarrow$ savoring beliefs $\rightarrow$ life satisfaction \\
Middle-aged crisis $\rightarrow$ interpersonal harmony $\rightarrow$ life \\
satisfaction
\end{tabular}

${ }^{* *} \mathrm{p}<.01, * * \mathrm{p}<.001$

\section{Discussion and Conclusion}

The purpose of this study is to investigate the relationship between Middle-aged crisis, wisdom, savoring belief, interpersonal harmony, and life satisfaction. The following are the results revealed through this study.

First, the differences in Middle-aged crisis, wisdom, savoring belief, interpersonal harmony, and life satisfaction according to the demographic and statistical characteristics of the middle-aged are as follows. Men were found to have lower Middle-aged crisis and interpersonal harmony than women. According to age, differences in wisdom, savoring beliefs, interpersonal harmony, and life satisfaction were significant. The results showed that women experienced higher Middle-aged crisis than men, and divorced women had higher Middle-aged crisis than married women. In the middle ages, the psychological burden is high due to the duty and responsibility to play a pivotal role in the family and society. In the case of women, they experience a crisis in the middle-aged period due to depression, helplessness, etc. due to career interruption due to childbirth and parenting after marriage.

Second, a correlation analysis was conducted to confirm the relationship between Middle-aged crisis, wisdom, savoring beliefs, interpersonal harmony, and life satisfaction. The results showed that Middle-aged crisis was negatively related to wisdom, savoring beliefs, interpersonal harmony, and life satisfaction. Wisdom had a positive correlation with savoring beliefs, interpersonal harmony, and life satisfaction. savoring beliefs have a positive correlation with interpersonal harmony, life satisfaction. Interpersonal harmony has a positive relationship with life satisfaction.

Third, this study only examined few variables in the relationship between Middle-aged crisis and life satisfaction. The higher the middle-aged crisis sub-factor, the lower the life satisfaction, and the magnitude of influence was found to be life dissatisfaction, loss of vitality, emotional crisis, child relationship dissatisfaction, and marital dissatisfaction. The higher the subfactor of wisdom, the higher the satisfaction of life, and the magnitude of influence was found in the order of positive life attitude, moderation and balance, cognitive competence, and empathic 
interpersonal relationship. The higher the enjoyment, the higher the satisfaction of life. The higher the interpersonal emotional factors, the higher the life satisfaction.

Fourth, the model evaluation criteria were calculated by applying the PLS algorithm and the blind folding procedure, and the internal VIF values among the potential variables were 1.00 2.25, which were all less than 5, which satisfied the Multicollinearity assumption. As a result of analyzing the estimated direct path coefficients, the higher the middle-aged crisis, the lower the wisdom, savoring beliefs, and interpersonal harmony. The higher wisdom, savoring belief, and interpersonal harmony, the higher the life satisfaction. As a result of estimating the indirect path, Middle-aged crisis had a significant effect on life satisfaction through wisdom, savoring beliefs and interpersonal harmony. Thus, wisdom, savoring beliefs, and interpersonal harmony all mediate the relationship between Middle-aged crisis and life satisfaction.

The limitations and suggestions of this study are as follows.

First, this study used random sampling method to select middle-aged men and women living in six cities. In future studies, the sampling rate of males and females by region should be similarly studied. Second, the scale used in this study was self-report. Due to the limitations of the self-report scale, in-depth analysis of middle-aged life satisfaction was not sufficient. Subsequent studies require more qualitative research on the life satisfaction of middle-aged men and women, or various approaches such as personal interview cases. Third, this study only studied a few variables in the relationship between Middle-aged crisis and life satisfaction. Subsequent research may require a variety of complex studies with more relevant variables.

\section{References}

[1] Economically Active Population Survey, Statistics Korea, (2018)

[2] W. S. Seo, A Study on the Relationship of Participation in Lifelong Learning to Life Satisfaction among the Elderly: Around the Case of Daegu Metropolitan City, Daegu University, Doctor's Thesis, (2009)

[3] S. H. Oh, A Study on the Relationship between Unrest, Life Satisfaction and Social Support in Single parent Family-Focused on Group Comparison between motherless family and fatherless family, Dongbang Culture Graduate University, Doctor's Thesis, (2015)

[4] E. A. Lee, The Relationships between the Ecosystem Variables and Middle-Aged Men's Psychological Adjustment, Chonbuk National University, Doctor's Thesis, (2007)

[5] K. J. Lee, A study on the influence of emotional crisis on mid-life women's psychosocial maturity : focusing on mediating effect of psychological well-being, Seoul Hanyoung University, Doctor's Thesis, (2018) 
[6] K. E. Lee, The influence of Stress and Resilience on Psychological well-being in Middle age, Sungshin Women's University, Master's Thesis, (2012)

[7] S. L. Lee, Counselor's Wisdom, Counseling Processes, and Outcomes, The Catholic University, Doctor's Thesis, (2008)

[8] S. M. Kwon, Positive Psychology, Hakjisa, (2008)

[9] H. S. Cho, S. M. Kwon, Y. J. Lim, Validation of the Korean Version of the Savoring Belief Inventory (SBI), Korean Journal of Clinical Psychology, (2010), Vol.29, No.2, pp.349-365, DOI: 10.15842/kjcp.2010.29.2.001

[10] Y. J. Kim, The Effects of Aging Anxiety, Family Strength and Interpersonal Relation of Middle-Aged Adults on Their Mid-Life Crisis, Dong-A University, Doctor's Thesis, (2017)

[11] A. S. Kim, G. Yoon, Factor Analyses of The Mid-Life Crisis Scale in The Korean Adults, Korean Journal of Developmental Psychology, (1991), Vol.4, No.1, pp.73-87.

[12] D. A. K. Hong, N. J. Lee, A Study of Coping Behavior with Midaged Women's Crisis, Korean Journal of Human Ecology, (2006), Vol.15, No.2, pp.227-237, UCI: G704-001335.2006.15.2.005

[13] O. K. Yang, Developing a Scale for Measuring Life Satisfaction, Korean Journal of Social Welfare, (1994), Vol.24, pp.157-198.

[14] M. H. Kim, Exploring the Concept of Wisdom and its Role on the Life among Middle-aged and Elder Adults in Korea, Seoul National University, Doctor's Thesis, (2008)

[15] F. B. Bryant, J. Veroff, Dimensions of Subjective Mental Health in American Men and Women, Journal of Health and Social Behavior, (1984), Vol.25, No.2, pp.116-135, DOI: 10.2307/2136664

[16] H. S. Cho, The Relationship between Savoring and Subjective Well-being, Seoul National University, Master's Thesis, (2008)

[17] S. H. Kim, G. H. Park, The Development of the Interpersonal Harmony Scale for University Students, Korea Journal of Counseling, (2008), Vol.9, No.2, pp.375-389, DOI: 10.15703/kjc.9.2.200806.375 